\title{
Erratum to: Excitability of the infraspinatus, but not the middle deltoid, is affected by shoulder elevation angle
}

\author{
Yin-Liang Lin ${ }^{1}$ Anita Christie ${ }^{1}$ Andrew Karduna ${ }^{1}$
}

Published online: 21 July 2015

(C) Springer-Verlag Berlin Heidelberg 2015

\section{Erratum to: Exp Brain Res (2015) 233:1837-1843 DOI 10.1007/s00221-015-4255-3}

Regrettably, there was an error in our calculation of the exponential parameter (m). Though errors led to wrong values and statistical analysis of $\mathrm{m}$, the conclusions of the study were not affected.

Although all of the $p$ values for the exponential parameter $(m)$ are still not statistically significant, their correct value, Table 1 and Fig. $3 b$ are given below:

- Middle deltoid $\left(0^{\circ}\right.$ compared to $\left.90^{\circ}\right): p=0.15$

- Infraspinatus $\left(0^{\circ}\right.$ compared to $\left.90^{\circ}\right): p=0.19$

- Percentage change from $0^{\circ}$ to $90^{\circ}$ (middle deltoid compared to infraspinatus): $p=0.91$

Table 1 The comparison of the percentage changes from $0^{\circ}$ to $90^{\circ}$ of arm elevation between the middle deltoid and infraspinatus by using a paired $t$ test

\begin{tabular}{lrrr}
\hline & $\begin{array}{l}\text { Deltoid } \\
\text { Mean (SD) }\end{array}$ & $\begin{array}{l}\text { Infraspinatus } \\
\text { Mean (SD) }\end{array}$ & $p$ \\
\hline MEP $_{\text {max }}(\%)$ & $-4.9(36.2)$ & $56.3(72.6)$ & 0.01 \\
Slope (\%) & $-4.7(49.2)$ & $-2.6(53.0)$ & 0.91 \\
Threshold (\%) & $3.6(13.9)$ & $0.1(14.2)$ & 0.41 \\
\hline
\end{tabular}

The online version of the original article can be found under doi:10.1007/s00221-015-4255-3.

Andrew Karduna

karduna@uoregon.edu

1 Department of Human Physiology, 1240 University of Oregon, Eugene, OR 97403-1240, USA
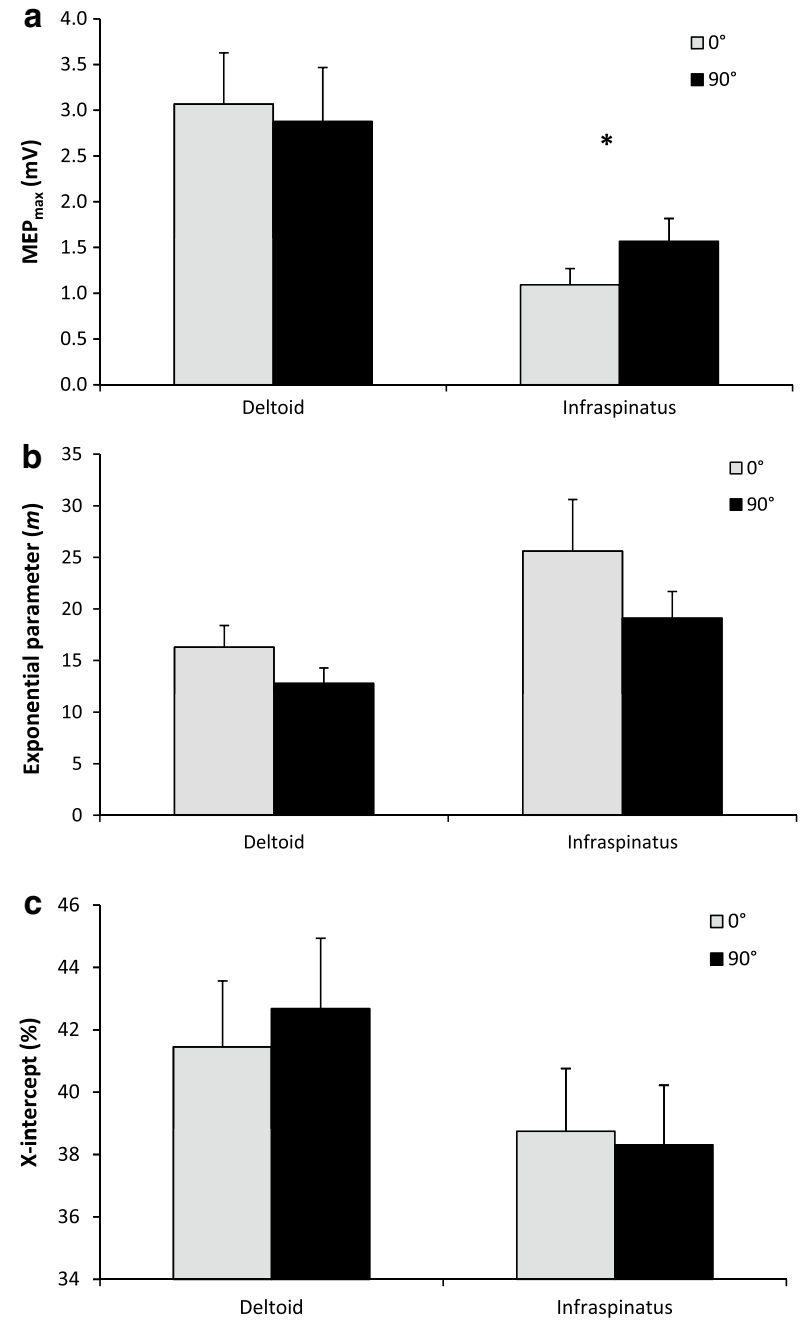

Fig. 3 Comparison of a plateau value $\left(\mathrm{MEP}_{\max }\right)$, b exponential parameter $(m)$, and, $\mathbf{c} x$-intercept between humeral elevation angles. ${ }^{*} p<0.05$ 